\title{
Mucosal airway laceration secondary to endobronchial ultrasonography
}

\author{
Amarinder Sandhu $\mathrm{MD}^{2}$, Edmundo Rubio $\mathrm{MD}^{2}$, Susanti le $\mathrm{MD}^{2}$, Michael Boyd $\mathrm{MD}^{1}$
}

\begin{abstract}
A Sandhu, E Rubio, S Ie, M Boyd. Mucosal airway laceration secondary to endobronchial ultrasonography. Can Respir J 2012;19(4):e31-e32.

Endobronchial ultrasound-guided transbronchial needle aspiration is becoming the standard of care for mediastinal sampling to diagnose and stage lung cancer. It is considered to be safe and rivals the gold standard, mediastinoscopy, in safety and accuracy. The present article describes a mucosal airway laceration and pneumothorax associated with the procedure.
\end{abstract}

Key Words: Bronchoscopy; Complications; Endobronchial ultrasound; Lung cancer

Cndobronchial ultrasound (EBUS) guidance has become routine in Ethe performance of transbronchial needle aspiration (TBNA) $(1,2)$. The procedure allows for more precise targeting of lesions, while minimizing potential complications (3). The procedure is generally regarded to be extremely safe; however, the unique scope design may be associated with complications. We present a case of an airway laceration, underscoring important aspects regarding the safety of this technique.

\section{CASE PRESENTATION}

An 81-year-old woman presented to the Carilion Clinic (Virginia, USA) with a right upper lobe (RUL) mass and mediastinal adenopathy seen on chest computed tomography. For staging, EBUS-guided TBNA of station 4R was performed. An Olympus BF-UC180F ultrasound bronchoscope (Olympus America, USA) was used, under general anesthesia, through a laryngeal mask airway. Six aspirate samples were obtained

\section{Une lacération des muqueuses respiratoires causée par une échographie endobronchique}

L'aspiration transbonchique à l'aiguille par échographie endobronchique est en voie de devenir la norme pour les prélèvements du médiastin visant à diagnostiquer et à évaluer le stade du cancer du poumon. Elle est considérée comme sécuritaire, sans compter que sa sécurité et sa précision rivalisent avec la médiastinoscopie, la norme d'excellence. Le présent article décrit une lacération des muqueuses respiratoires et un pneumothorax découlant de l'intervention.

using a 21-gauge ViziShot NA-201SX-4021 needle (Olympus America, USA). While awaiting rapid onsite cytological examination, the EBUS scope was advanced to inspect the RUL. On retraction of the EBUS scope, a mucosal tear was noted. The EBUS scope was removed. Inspection of the airways using a smaller diagnostic scope (Olympus BF-Q 180) confirmed the presence of a $10 \mathrm{~mm}$ long mucosal laceration along the lateral wall of the RUL entry. The depth of the laceration was estimated to be $2 \mathrm{~mm}$ to $3 \mathrm{~mm}$, thus also involving the submucosa (Figure 1). The RUL was sampled with a Cellebrity M00516010 cytology brush (Boston Scientific, USA). A postprocedure chest roentogram demonstrated a pneumothorax (Figure 2), which was successfully managed with a chest tube. The pathology of the TBNA was adenocarcinoma. Further imaging revealed metastatic disease. Given her poor functional status, the patient and her family opted for hospice care. She passed away peacefully in the hospice unit.

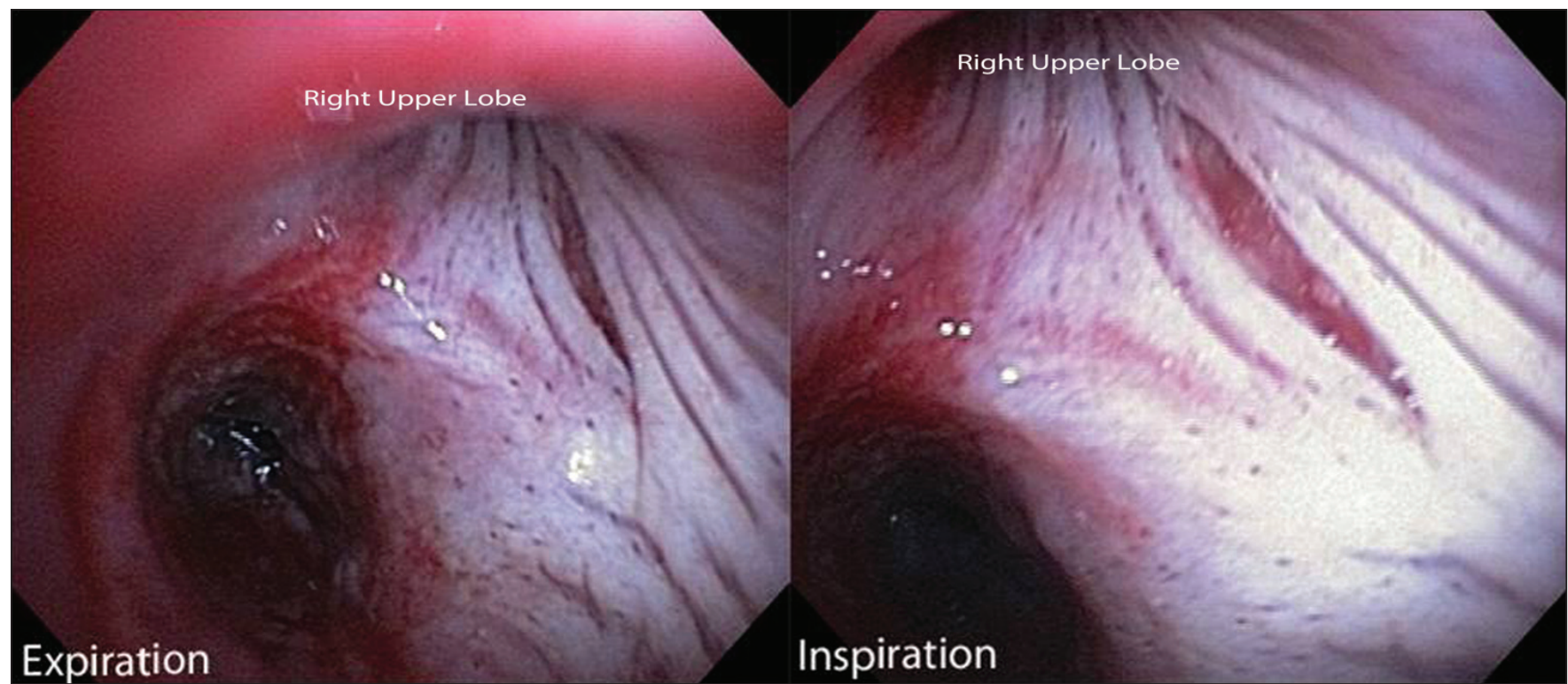

Figure 1) Mucosal laceration following endobronchial ultrasound (expiration and inspiration)

Section of Pulmonary, Critical Care, Environmental and Sleep Medicine, Carilion Clinic, Virginia Tech Carilion School of Medicine, Roanoke, Virginia, USA

Correspondence: Dr Michael Boyd, Section of Pulmonary, Critical Care, Environmental, and Sleep Medicine, Carilion Clinic, Virginia Tech Carilion School of Medicine, 1906 Belleview Avenue, Roanoke, Virginia 24014, USA. Telephone 540-853-0186,

fax 540-983-1133, e-mail mboyd@carilionclinic.org 


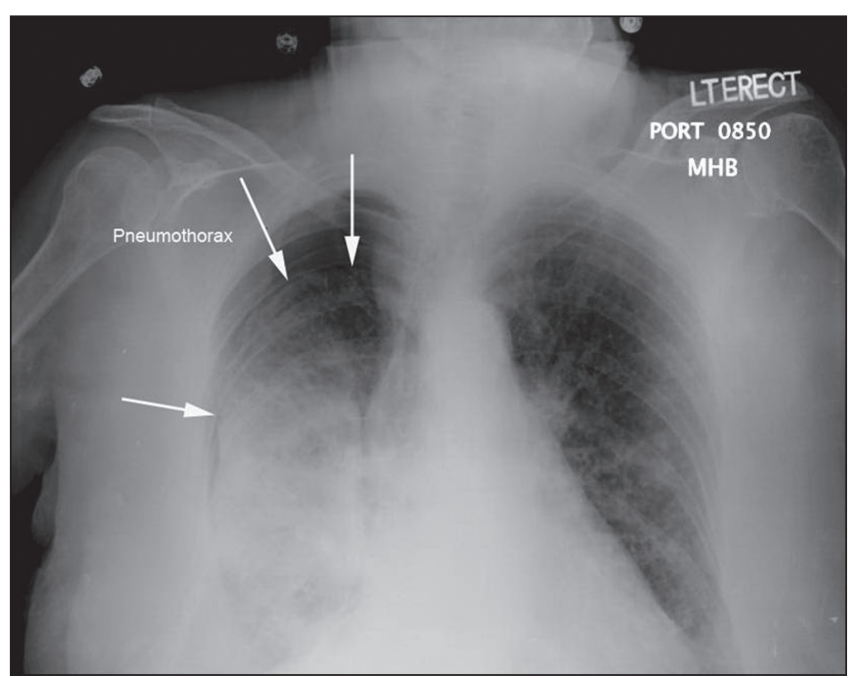

Figure 2) Pneumothorax (arrows) following endobronchial ultrasound and mucosal laceration

\section{DISCUSSION}

EBUS, while relatively new, is rapidly being adopted by many centres in the United States because it is a minimally invasive procedure as opposed to the gold standard, mediastinoscopy. EBUS is generally considered to be safe but, as with any new technology, it is conceivable that complications may be recognized as the technology becomes more widely used (1-3). Because there is currently no standardized training for EBUS, novice or inexperienced bronchoscopists using this new technology may encounter a higher number of complications than previously reported.

Yasufuku (3) reported a large series of EBUS procedures with no complications. Meta-analyses suggest that only minimal complications should be expected, namely agitation, cough and bleeding at the puncture site $(1,2)$. Isolated complications have been reported to include transient bacteremia, lung and mediastinal abscesses, metallic particles embedded in the lymph nodes, and inflammatory polyps or granulation tissue at the aspiration site (5-9), none of which appear to be related to the use of EBUS, but rather to the performance of TBNA.

The performance of EBUS may, nevertheless, have specific related concerns. Recently, an airway laceration after EBUS performance, presumably related specifically to the use of this instrument, was reported (10). In general, when using the EBUS scope, procedures can take longer, therefore increasing patient exposure to anesthetia and sedation, thus putting patients at potentially added anesthesia-related risk.

The design of the EBUS scope is physically different from traditional bronchoscopes. It is not only larger, but has a rigid tip with a chisel-like shape and incorporates the ultrasound sensor. The camera is at $30^{\circ}$ to the long axis of the scope, thus making navigation different. To obtain a centralized view of the airway, the scope must be retroflexed, exposing the sharp edge of the 'chisel' toward the airway wall. Such retroflexion should be avoided while navigating because it may cause airway trauma. Given these inherent design properties, the EBUS scope is not an adequate instrument for airway inspections.

Our patient's pneumothorax, while possibly related to the brush procedure, was likely related to the airway laceration. In fact, the laceration can be explained to be the direct result of trauma caused by the EBUS scope.

\section{CONCLUSION}

We suspect that there may be under-reporting of complications, and believe it is important to report these cases to alert physicians of the potential pitfalls of this new procedure. We also encourage physicians to avoid inspecting the airways with an EBUS scope, and encourage manufacturers to continue improving the design of these novel instruments. We also recommend that this procedure be performed either personally or directly supervised by an experienced bronchoscopist.

IN MEMORIUM: This article is dedicated to the memory of Dr Amarinder Sandhu, a wonderful family man whose colleagues will remember him as a brilliant physician, student and teacher.

\section{REFERENCES}

1. Varela-Lema L, Fernández-Villar A, Ruano-Ravina A. Effectiveness and safety of endobronchial ultrasound-transbronchial needle aspiration: A systematic review. Eur Respir J 2009;33:1156-64.

2. Adams K, Shah PL, Edmonds L, Lim E. Test performance of endobronchial ultrasound and transbronchial needle aspiration biopsy for mediastinal staging in patient with lung cancer: Systematic review and meta-analysis. Thorax 2009;64:757-62.

3. Yasufuku K. Complications of endobronchial ultrasound-guided transbronchial needle aspiration: Editorial. J Bronchol Intervent Pulmonol 2010;17:287-8.

4. Haas AR. Infectious complications from full extension endobronchial ultrasound transbronchial needle aspiration. Eur Respir J 2009;33:935-8.

5. Steinfort DP, Johnson DF, Irving LB. Incidence of bacteraemia following endobronchial ultrasound-guided transbronchial needle aspiration. Eur Respir J 2010;36:28-32.

6. Parker KL, Bizekis CS, Zervos MD. Severe mediastinal infection with abscess formation after endobronchial ultrasound-guided transbrochial needle aspiration. Ann Thorac Surg 2010;89:1271-2.

7. Huang CT, Chen CY, Ho CC, Yu CJ. A rare constellation of empyema, lung abscess, and mediastinal abscess as a complication of endobronchial ultrasound-guided transbronchial needle aspiration. Eur J Cardiothorac Surg 2010;40:264-5.

8. Gounant V, Ninane V, Janson X,et al. Release of metal particles from needles used for transbronchial needle aspiration. Chest 2011;139:138-43.

9. Gupta R, Park HY, Kim H, Um SW. Endobronchial inflammatory polyp as a rare complication of endobronchial ultrasoundtransbronchial needle aspiration. Interact Cardiovasc Thorac Surg 2010;11:340-1.

10. Liberman M, Duranceau A, Martin J, Thiffault V, Ferraro P. Major airway laceration secondary to endobronchial ultrasound transbronchial lymph node biopsy. J Bronchol Intervent Pulmonol 2010;17:264-5. 


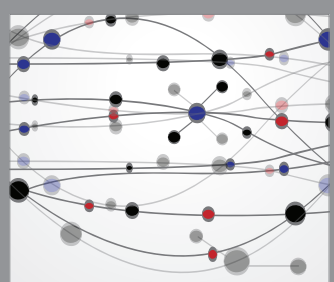

The Scientific World Journal
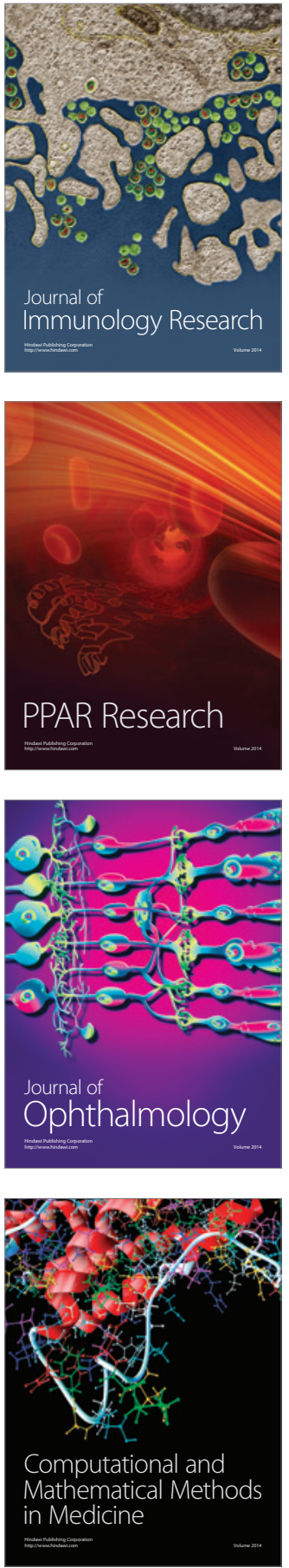

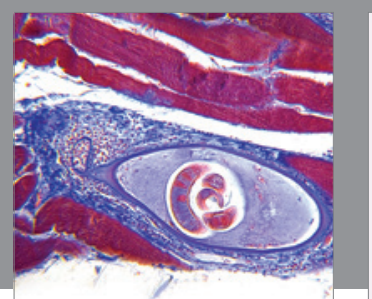

Gastroenterology Research and Practice

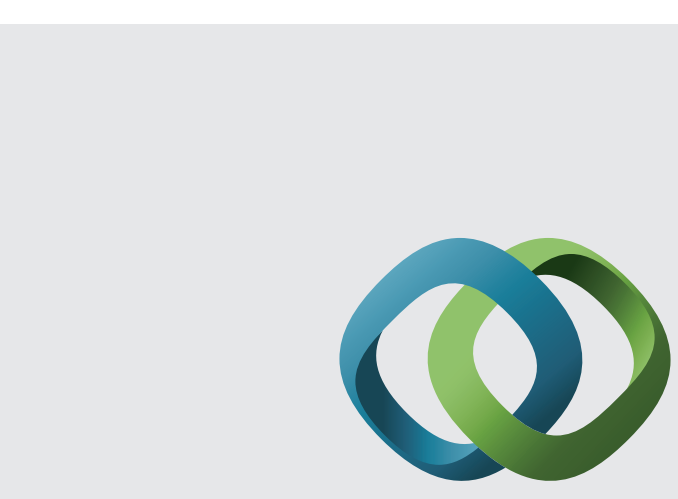

\section{Hindawi}

Submit your manuscripts at

http://www.hindawi.com
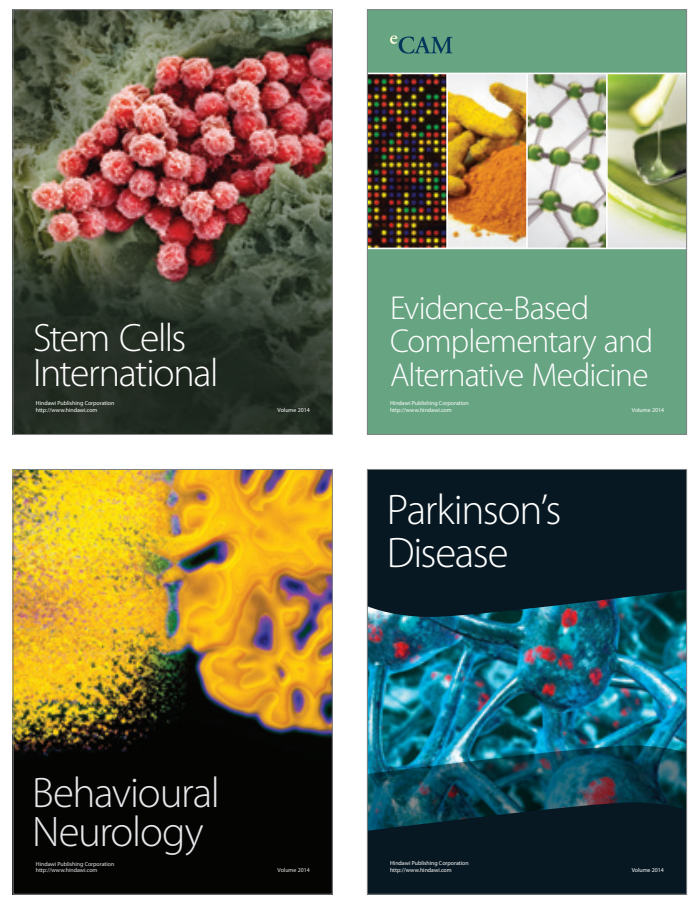
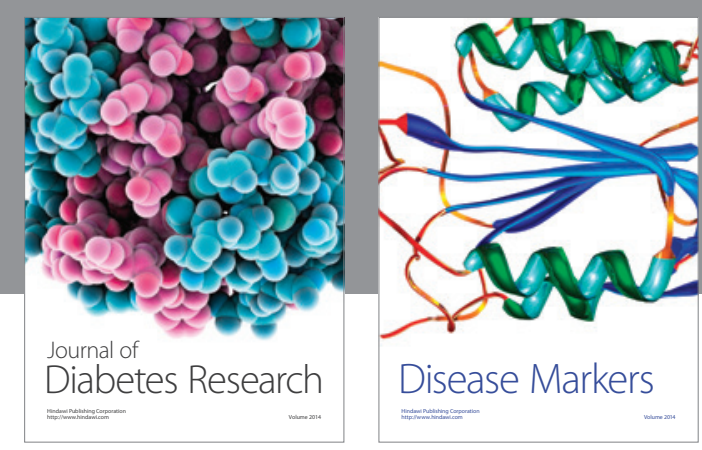

Disease Markers
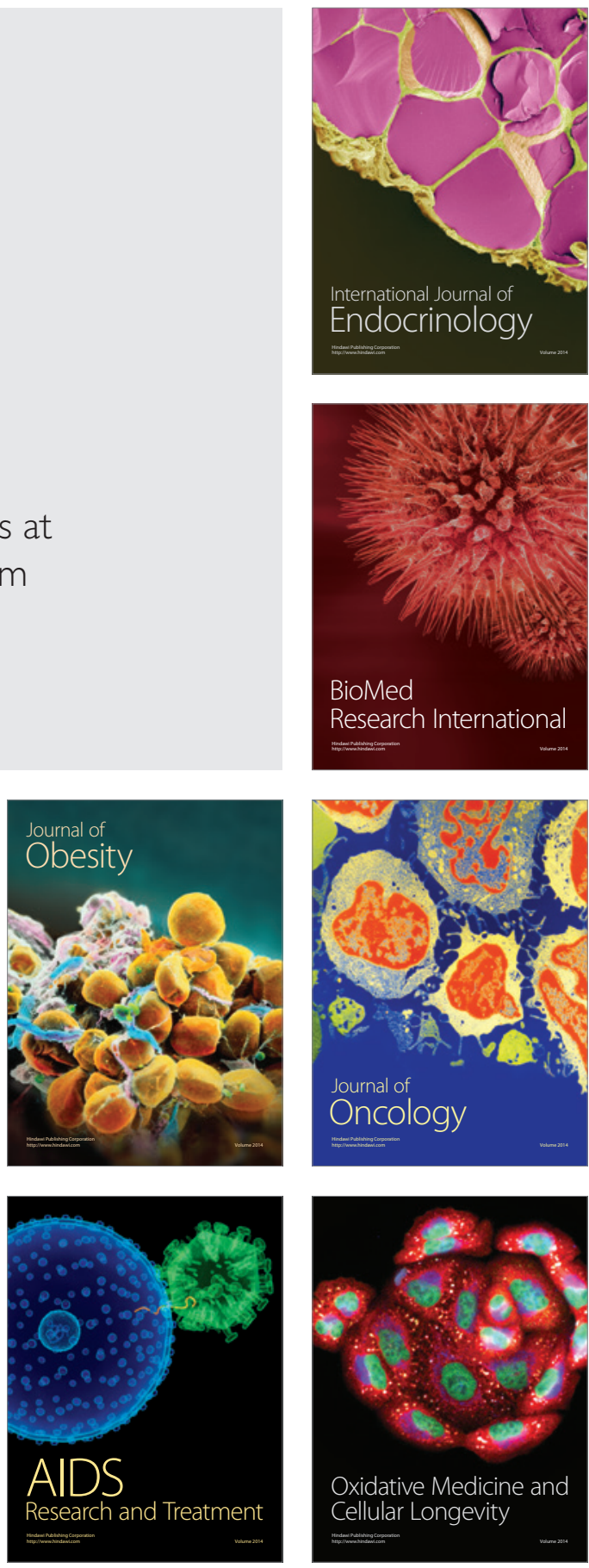